\title{
Investigation of Toxicity and Systemic Exposure of Bioactive Compounds of Aqueous Leaf Extract of Azadirachta indica A. Juss (Meliaceae) on Wistar Rats
}

\author{
Tembe Fokunang Estella ${ }^{1}$, Ndi Sirri Akwen ${ }^{1}$, Njinkio Borgia Nono ${ }^{1}$, Tsabang Nole ${ }^{1}$, \\ Ndikum Valentin Nchafor ${ }^{2}$, Ngameni Bathelemy ${ }^{3}$, Nguefack Tsague Georges ${ }^{4}$, Charles Fokunang ${ }^{1, *}$, \\ Ngadjui Bonaventure Tchaleu ${ }^{2}$ \\ ${ }^{1}$ Department of Pharmaco-Toxicology and Pharmacokinetics, Faculty of Medicine and Biomedical Sciences, University of Yaoundé 1, \\ Yaoundé, Cameroon \\ ${ }^{2}$ Department of Pharmacology and Traditional medicine, Faculty of Medicine and Biomedical Sciences, University of Yaoundé 1, Yaoundé, \\ Cameroon \\ ${ }^{3}$ Department of Pharmacognosy and Therapeutic chemistry, Faculty of Medicine and Biomedical Sciences, University of Yaoundé 1, \\ Yaoundé, Cameroon \\ ${ }^{4}$ Department of Public Health, Faculty of Medicine and Biomedical Sciences, University of Yaoundé 1, Yaoundé, Cameroon
}

Email address:

charlesfokunang@yahoo.co.uk (C. Fokunang)

*Corresponding author

To cite this article:

Tembe Fokunang Estella, Ndi Sirri Akwen, Njinkio Borgia Nono, Tsabang Nole, Ndikum Valentin Nchafor, Ngameni Bathelemy, Nguefack Tsague Georges, Charles Fokunang, Ngadjui Bonaventure Tchaleu. Investigation of Toxicity and Systemic Exposure of Bioactive Compounds of Aqueous Leaf Extract of Azadirachta indica A. Juss (Meliaceae) on Wistar Rats. Journal of Drug Design and Medicinal Chemistry. Vol. 5, No. 1, 2019, pp. 10-17. doi: 10.11648/j.jddmc.20190501.12

Received: April 26, 2019; Accepted: May 28, 2019; Published: June 24, 2019

\begin{abstract}
Conventional medications used to treat ulcers are not easily accessible to remote areas, costly and not without side effects, thus causing many patients residing in rural areas to resort to herbal means of treatment. World Health Organization records that at least $80 \%$ of the world's population depends on herbal medicinal products. Herbal therapy is the belief that it will promote healthier living. Azadirachta indica is a tree extensively spread in the Northern parts and sparsely distributed in the Northwest Region of Cameroon, used as a remedy for several pathologies, amongst which we have gastric ulcers which is our area of interest. The objective of this study was to evaluate the acute oral toxicity (420 OECD guidelines), systemic exposure and biochemical parameters of toxicity of Azadirachta indica. A. Juss on Wistar rats. Various biochemical parameters such as the: MDA, Catalase, Glutathione, Pepsin, SOD, ASAT, ALAT, Creatinine, XO, and total proteins, were quantified. The acute oral toxicity was of $2000 \mathrm{mg} / \mathrm{Kg}$ single dose and compared to a control group which was administered tap water. The administration of $2000 \mathrm{mg} / \mathrm{Kg}$ was well tolerated and no death was recorded throughout the fourteen days of observation. No toxic effects were recorded in the organs, implying that at the dose of $2000 \mathrm{mg} / \mathrm{Kg}$, Azadirachta indica was safe. Azadirachta indica aqueous leaf extract contains active metabolites coumarins, catechic tannins, polyphenols, tannins, flavonoids and phlobotannins that were bioavailable in systemic circulation. Showed bioavailability at the tested doses $(12.5,25$ and $50 \mathrm{mg} / \mathrm{Kg})$, with the presence of phytochemicals being dose dependent. A clean toxicity profile, with just a slight increase in the level of creatinine.
\end{abstract}

Keywords: Azdiracthta Indica, Systemic Exposure, Toxicity Bioactive Compounds Wistar Rats

\section{Introduction}

Traditional medicine has a long history and according to $\mathrm{WHO}$, it is the sum total of the knowledge, skill, and practices based on the theories, beliefs, and experiences indigenous to different cultures, whether explicable or not, used in the maintenance of health as well as in the prevention, diagnosis, improvement or treatment of physical and mental 
illness [1-5]. Large sections of the population in developing countries still rely on traditional practitioners and herbal medicines for their primary care; in Africa up to $90 \%$ and in India $70 \%$ of the population depend on traditional medicine to help meet their health care needs. In China, traditional medicine accounts for around $40 \%$ of all health care delivered [5-7].

The extensive use of traditional medicines could be backed up by several reasons, some of which include, they are more affordable, more closely correspond to the patient's ideology, allays concerns about the adverse effects of chemical (synthetic) medicines, satisfies a desire for more personalized health care, and allows greater public access to health information [2, 8-10]. In some parts of the world, traditional medicine is still considered as alternative medicine. Alternative medicine has been simply defined by WHO as a broad set of health care practices that are not part of that country's own tradition or conventional medicine and are not fully integrated into the dominant health-care system. They are used interchangeably with traditional medicine in some countries. $[1,11]$

According to a survey by the National Center for Complementary and Alternative Medicine, herbal medicine (plant-derived materials or products with therapeutic or other human health benefits which contain either raw or processed ingredients from one or more plants or the usage of natural products other than vitamins and minerals was the most commonly used alternative medicine (18.9\%) when all use of prayer was excluded [3, 12-15].

Herbs have been extensively used in different domains of life; nutritional relevance, recreation, disease remedies, ornamentation, fencing, etc. Herbal medicines have been widely utilized as effective remedies for the prevention and treatment of multiple health conditions for centuries by almost every known culture [16]. The first documented records of herbal medicine use date back 5,000 years in China. Similarly, India's Ayurvedic medicine tradition is thought to be more than 5,000 years old and herbal medicines remain an essential component of its practice. Today, vast populations of certain countries still depend on herbal medicines to address their healthcare needs [4, 17-20].

Medicinal plants (plants which have been used for medical purposes at one time or another, and which, although not necessarily a product available for marketing, is the original material of herbal medicines [21-23]) long played important roles in the treatment of diseases all over the world. Healing with medicinal plants is as old as mankind itself. The connection between man and his search for drugs in nature dates from the far past, of which there is ample evidence from various sources: written documents, preserved monuments, and even original plant medicines [5, 24-26].

Given the limitations associated to conventional medicines poor access to medication in rural areas, informed choice to reduce incidence of side effects in urban areas, costly medications - many people tend to use herbal or traditional medicines. Regardless of why an individual uses it, traditional medicine provides an important health care service whether people have physical or financial access to allopathic medicine, and it is a flourishing global commercial enterprise [27].

Currently, herbs are applied to the treatment of chronic and acute conditions and various ailments and problems such as cardiovascular disease, peptic ulcer disease, prostate problems, depression, inflammation, and to boost the immune system, to name but a few $[21,28]$. The use of the Neem Tree dates as far back as mankind. Neem is an omnipotent tree and a sacred gift of nature. Neem tree is mainly cultivated in the Indian subcontinent. Neem is a member of the mahogany family, Meliaceae [3, 29]. Today it is known by the botanical name Azadirachta indica (A. indica) A. Juss. Neem has been used extensively by humankind to treat various ailments before the availability of written records which recorded the beginning of history. Very limited literature is available on the treatment of PUD by $A$. indica $[11,29-31]$. It has a high tolerance of harsh environments, grows poorly in waterlogged and cold regions and grows best in altitudes of sea level to 800 above level in well drained soils.

\section{Materials and Methods}

\subsection{Study Site, Research Design}

This study was carried out in Laboratory for Preclinical Animal Studies and Toxicology Research of the Faculty of Medicine and Biomedical Sciences, FMBS, University of Yaoundé I.

The study was an experimental in vitro and in vivo design done in albino rats of Wistar strain conducted between the $6^{\text {th }}$ November 2017 to May 2018.

\subsection{Ethical Considerations}

Ethical approval was demanded from the institutional review board of the Faculty of Medicine and Biomedical Sciences. Authorization was obtained from the administration of the FMBS, to work in the animal house of this faculty. The OECD Guidelines for the use of animals in preclinical studies was applied

\subsection{Plant Material - Azadirachta Indica}

\subsubsection{Harvesting and Identification}

The fresh leaves were harvested from a Neem plant growing in Ndop, capital of the Ngo Ketunjia Division of the Northwest Region, Cameroon, in the compound of Mr. Saki Madi Mahamat. These leaves were taxonomically identified and authenticated at the National Herbarium of Cameroon as Azadirachta indica leaves by Dr. Tchiengue Barthelemy. The sample was given the voucher code No 4447/SRFK.

We then proceeded to wash and dry the leaves in a shade, on mats placed on a flat surface. When dried, the leaves were ground, sieved to get fine powder and stored in airtight containers before extraction.

\subsubsection{Extraction of Leaf Powder}

There are several existing methods of extracting a plant but because this research is aimed at proving the presence of an activity claimed traditionally, we decided to use the 
traditional method; maceration.

In this process, $150 \mathrm{~g}$ of the coarsely powdered crude plant was put in a stoppered container with $1.5 \mathrm{~L}$ of distilled water and allowed to stand at room temperature for a period of 48 hours with frequent agitation until the soluble matter has dissolved. The mixture was then strained, the marc (the damp solid material) was pressed, and the combined liquids were clarified by filtration using Whatman paper and collected the supernatant. This filtrate was evaporated and the extract collected. The percentage yield was then calculated:

$$
\text { Percentage yield }=\frac{\text { Mass of extract obtained } * 100}{\text { Mass of powder initially used }}
$$

\subsection{Animal Material}

The experiments were done on adult albino rats of Wistar strain, gotten from the Animal House of FMBS, UY1.

\subsubsection{Selection and Feeding of Rats}

Wistar strain (Rattus norvegicus) albino rats were used. All animals used were bred in the FMBS animal house under favorable conditions of $12 \mathrm{~h}$ of light and $12 \mathrm{~h}$ of day. The rats were aged between 7 and 12 weeks, with average weight $203 \pm 32$ for the antiulcer activity. Also, for this activity, only male rats were used because literature demonstrates that the male gender is more prone to having ulcers. Both male and female rats were used for the toxicity studies, with average mass $118 \pm 23$.

The animals were fed with a diet, consisting of corn meal (45\%), wheat flour $(20 \%)$, fish meal $(20 \%)$, soybean meal (10\%), palm kernel (5\%), bone flour for calcium intake $(0.98 \%)$, cooking salt $(0.5 \%)$ and vitamin complex $(0.5 \%)$. They were also allowed free access to regular tap water.

\subsubsection{Accommodation of Rats}

For each study, the animals were separated in different cages, with distinct and clear labels. The cages were made of plastic material with iron tops/doors and a space for food and water was made available. The floors were lined with saw dust to keep it dry. In conditions where the rats had to be starved, they were put in metabolic cages made of stainless steel material with spaced bars, allowing the feces to fall through, thus preventing them from eating their feces. In each cage, the tails of rats were marked with bold markers, with the number of lines denoting the rat number. These animals were then crosschecked to make sure that they were in good health and kept in natural environmental conditions (12h of light and $12 \mathrm{~h}$ of darkness). Each day, the rats were fed with the above mentioned meal and given water ad lib.

\subsection{Administration of Test Substances}

The ulcerogenic agent, reference drugs or aqueous leaf extract were administered using an intubation needle, fitted into syringes of different volumes. Depending on the study, different volumes and doses of these substances were calculated and given to the rats according to their individual weights.

\subsubsection{Acute Toxicity}

The animals were randomly selected, marked to permit individual identification and kept in their cages for acclimatization to laboratory conditions for at least five days before the experiment. Animals should be fasted prior to the administration of the substance; food were deleted, but not water, overnight. The extracts were administered in a single dose by gavage. The doses were prepared just prior to administration. After the period of fasting, the animals were weighed and then the extracts were administered. After administration of the substance, the animals were starved again, for 3 to 4 hours. Each step required three animals. For the initial dose, $2000 \mathrm{mg} / \mathrm{kg}$ body weight was chosen. The administration of the next lower dose was great if mortality was observed among animals. For 14 days, we observed the various manifestations of toxicity: salivation, diarrhea, lethargy, sleep and coma. The individual weight of each animal was determined shortly before administration of the test substance and then at least once a week. At the end of the test, the rats were euthanized for 14 days [32]. After a blood sample from the retro orbital sinus was collected for determination of blood biochemical parameters. Organs were immediately isolated, washed with cold saline and fixed in a neutral solution of $10 \%$ buffered formalin for histopathological evaluation

\subsubsection{Zoo Technical Criteria}

On day one, the animals were observed for one hour for abnormal behaviors like cleaning, abnormal postures, hyper/hypo activity, tremors, scratching and myoclonia. The animals' behavior were followed up with respect to feeding, water consumption and weight gain were observed and recorded throughout the fourteen days of studies. This was done every morning before 9:00 am

\subsubsection{Preparation and Administration of the Extract}

We prepared a $200 \mathrm{mg} / \mathrm{ml}$ concentration solution. $20 \mathrm{~mL}$ of solution was obtained from $4000 \mathrm{mg}$ of extract and distilled water (sufficient for $20 \mathrm{~mL}$ ). Then, the mixture was homogenized using a magnetic stirrer. From this solution, a dose of $2000 \mathrm{mg} / \mathrm{kg}$ of aqueous extract was administered to the male and female test groups according to their weight, while the control groups received distilled water. The animals were again deprived of food for four hours.

\subsection{Quantification of Toxicity Biochemical Parameters}

\subsubsection{Evaluation of the Renal Activity}

\section{Creatinine quantification (CHRONOLAB KIT)}

The assay is based on the reaction of creatinine with sodium picrate as described by JAFFÉ. Creatinine reacts with alkaline picrate forming a red complex. The time interval chosen for measurements avoids interferences from other serum constituents. The intensity of the color formed is proportional to the creatinine concentration in the sample。

\subsubsection{Quantification of ALAT (CHRONOLAB KIT)}

Alanine aminotransferase (ALT) or Glutamate pyruvate transaminase (GPT) catalyzes the reversible transfer of an amino group from alanine to $\alpha$-ketoglutarate forming glutamate and pyruvate. The pyruvate produced is reduced to lactate by lactate dehydrogenase (LDH) and NADH: 
The rate of decrease in concentration of NADH, measured photo metrically, is proportional to the catalytic concentration of ALT present in the sample

\subsubsection{Quantification of ASAT (CHRONOLAB KIT)}

Aspartate aminotransferase (AST) formerly called glutamate oxaloacetate (GOT) catalyses the reversible transfer of an amino group from aspartate to $\alpha$-ketoglutarate forming glutamate and oxalacetate. The oxalacetate produced was reduced to malate by malate dehydrogenase (MDH) and NADH:

$$
\begin{gathered}
\text { Aspartate }+\alpha \text {-Ketoglutarate } \rightarrow \text { AST Glutamate }+ \\
\text { Oxalacetate }
\end{gathered}
$$

$$
\text { Oxalacetate }+\mathrm{NADH}+\mathrm{H}^{+} \rightarrow \mathrm{MDH} \text { Malate }+\mathrm{NAD}^{+}
$$

The rate of decrease in concentration of NADH, measured photometrically, is proportional to the catalytic concentration of ASAT present in the sample

\subsection{Evaluation of Systemic Drug Exposure}

The systemic exposure of a drug determines to an extent, the bioavailability or absorption. Many in vitro studies indicated that neem possesses various bioactivities; however, a poor bioavailability may make them largely ineffective in vivo. Absorption levels are therefore of special interest. The same method used in phytochemical screening for secondary metabolites in the plant extract was used in evaluating the systemic exposure. After exposure of the rats to extract treatment, blood samples were collected and used phytochemical screening for metabolites.

From the curative activity, the least dose which offers the best ulcer healing was used. The animals was administered this dose and at different time points, blood samples were collected from the tail vein and centrifuged. The plasma was extracted and screened for the presence of different secondary metabolites, referencing from what was found during the screening of the plant extract.

\subsection{Statistical Analysis}

The results were expressed in terms of mean \pm standard deviation. The comparisons between the groups were analyzed using one-way analysis of variance, the ANOVA test followed by Turkey's Kramer post hoc test using the GraphPad Instat version 5.0 software. A P-value of less than 0.05 was considered statistically significant.

\section{Results}

\subsection{Extraction Yield}

The 1:1 ratio aqueous extraction of the Azadirachta indica leaf yielded $11.27 \%$.

\subsubsection{Acute Toxicity}

Zootechnical parameters- observation of behaviour of rats after administration of plant extract.

Observation of test groups of male and female treated rats from 0-30 days showed no abnormal posture, vocalization, myoclonia and hypo activity. There were indications of scratching,

\begin{tabular}{|c|c|c|c|}
\hline \multicolumn{2}{|c|}{ Observation of test groups (male and female) } & \multirow{2}{*}{$\begin{array}{l}\text { Day one, } \mathbf{0}-30 \text { minutes after administration of plant substance } \\
+++\end{array}$} & \multirow{2}{*}{$\begin{array}{l}\text { Days two to fourteen } \\
-\end{array}$} \\
\hline \multirow{8}{*}{ Appearance } & Cleaning & & \\
\hline & Abnormal posture & - & - \\
\hline & Hyper activity & ++ & - \\
\hline & Tremors & + & - \\
\hline & Vocalization & - & - \\
\hline & Scratching & ++ & - \\
\hline & Myoclonia & - & - \\
\hline & Hypo activity & - & - \\
\hline
\end{tabular}
hyperactivity, tremors and cleaning as shown in Table 1.

Table 1. Observation of behavior of rats after administration of NLEa.

\subsubsection{Weights}

The average weights of the control groups and animal groups receiving the plant substance increased from day one to day fourteen, with a slight decrease in the weight of the test males on day eight (Figure 1). These statistics showed no significant variation between the weights of the test and control groups, with a $p$-value $>0.05$.

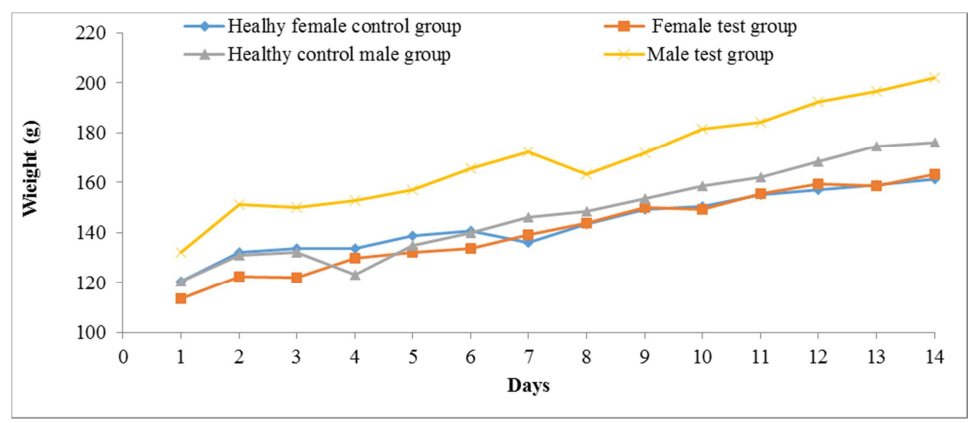

Figure 1. Kinetic evolution of weight during acute oral toxicity evaluation. 


\subsubsection{Food Intake}

As concerns the food intake, a non-significant decrease was observed in the test females. Contrarily, an increase in the test males was observed, though not significant (Table 2).

\subsubsection{Water Intake}

A significant increase in the water intake was observed in both groups of animals that received the NLEa, with a $p$-value $<$ 0.01, when compared to the control groups of animals (Table 2).

Table 2. Zootechnical parameters of acute oral toxicity of NLEa.

\begin{tabular}{lllll}
\hline Parameters & Female control & Female test & Male control & Male test \\
\hline Weight gain $(\mathrm{g})$ & $41,00 \pm 6,56$ & $50,00 \pm 10,12$ & $55,60 \pm 6,54$ & $81,40 \pm 26,38$ \\
Food intake $(\mathrm{g})$ & $169,62 \pm 11,41$ & $155,31 \pm 66,64$ & $144,85 \pm 46,33$ & $207,69 \pm 75,44$ \\
Water intake $(\mathrm{ml})$ & $124,15 \pm 19,67$ & $176,08 \pm 31,08 * *$ & $169,38 \pm 44,78$ & $232,08 \pm 55,40 * *$ \\
\hline
\end{tabular}

The results are expressed in average \pm standard deviation $(n=5)$.

\subsection{Relative Weight of Organs}

There was no significant difference in the weight of organs between the various test groups

Table 3. Relative weight of organs.

\begin{tabular}{|c|c|c|c|c|c|}
\hline Organs & & Control male & Test male & Control female & Test female \\
\hline Liver & & $4,25 \pm 0,20$ & $4,03 \pm 1,15$ & $4,03 \pm 1,13$ & $3,98 \pm 1,11$ \\
\hline Brain & & $0,86 \pm 0,07$ & $0,76 \pm 0,23$ & $0,99 \pm 0,25$ & $0,90 \pm 0,25$ \\
\hline Lungs & & $0,91 \pm 0,21$ & $0,88 \pm 0,26$ & $0,69 \pm 0,23$ & $0,70 \pm 0,22$ \\
\hline Pancreas & & $0,62 \pm 0,24$ & $0,29 \pm 0,23$ & $0,43 \pm 0,20$ & $0,39 \pm 0,17$ \\
\hline Heart & & $0,30 \pm 0,03$ & $0,29 \pm 0,08$ & $0,32 \pm 0,08$ & $0,31 \pm 0,08$ \\
\hline \multirow{2}{*}{ Kidneys } & Left & $0,34 \pm 0,04$ & $0,31 \pm 0,09$ & $0,34 \pm 0,09$ & $0,33 \pm 0,09$ \\
\hline & Right & $0,35 \pm 0,04$ & $0,32 \pm 0,09$ & $0,36 \pm 0,09$ & $0,35 \pm 0,09$ \\
\hline \multirow{2}{*}{ Adrenal glands } & Left & $0,01 \pm 0,003$ & $0,01 \pm 0,005$ & $0,01 \pm 0,006$ & $0,02 \pm 0,006$ \\
\hline & Right & $0,01 \pm 0,005$ & $0,01 \pm 0,005$ & $0,02 \pm 0,005$ & $0,02 \pm 0,006$ \\
\hline \multirow{2}{*}{ Testicles /Ovaries } & Left & $0,54 \pm 0,07$ & $0,50 \pm 0,15$ & $0,04 \pm 0,002$ & $0,03 \pm 0,002$ \\
\hline & Right & $0,55 \pm 0,07$ & $0,50 \pm 0,15$ & $0,03 \pm 0,002$ & $0,03 \pm 0,002$ \\
\hline
\end{tabular}

The results are expressed in average \pm standard deviation $(n=5)$.

\subsection{Zootechnical Parameters of Acute oral Toxicity of NLEa}
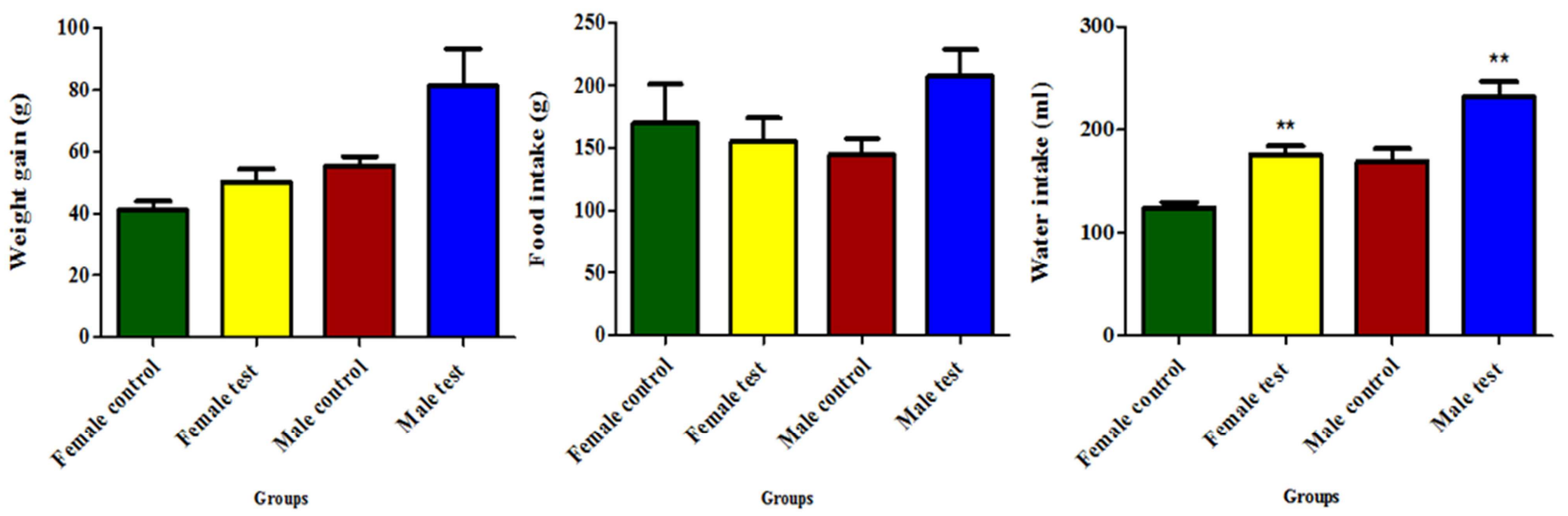

Figure 2. Zootechnical parameters of acute oral toxicity of NLEa.

\subsection{Biochemical Parameters of Acute Oral Toxicity}

Various enzymes, that served as organic markers were analyzed for further insight to the acute toxic effect of the aqueous Neem extract. Administration of the NLEa caused a significant increase in total proteins and creatinine in the test groups when compared to the control groups with a $p$-value $<$
0,001. On the other hand, the administration showed a nonsignificant decrease of ASAT and a non-significant increase of ALAT on male test groups (Table 4). There was no difference observed in the levels of ASAT and ALAT in the female test groups. The biochemical parameters are shown in the table (Table 4). 
Table 4. Biochemical parameters of acute toxicity Parameters.

\begin{tabular}{lllll}
\hline & Control female & Test female & Male control & Male test \\
\hline Total proteins (mg/dl) & $13,81 \pm 3,20$ & $61,13 \pm 2,72^{* * *}$ & $13,74 \pm 2,30$ & $66,83 \pm 4,45^{* * *}$ \\
Creatinine (UI/L) & $14,31 \pm 1,46$ & $5,59 \pm 1,74^{* * *}$ & $9,26 \pm 1,46$ & $4,90 \pm 1,04^{* * *}$ \\
ASAT (UI/L) & $23,28 \pm 12,02$ & $8,82 \pm 1,21$ & $23,51 \pm 20,19$ & $10,66 \pm 0,77$ \\
ALAT (UI/L) & $18,74 \pm 9,64$ & $18,70 \pm 3,38$ & $10,83 \pm 1,05$ & $21,67 \pm 0,75$ \\
\hline
\end{tabular}

\subsection{Evaluation of Systemic Exposure}

The blood serum was tested for the presence of secondary metabolites which were originally present when the NLEa was screened. There was detected bioavailability of the following metabolites mucilage, catechic tannins, flavonoids, total polyphenols at $12.5 \mathrm{mg}, 25 \mathrm{mg}, 50 \mathrm{mg}$ of NLE in the blood serum measured. Flavonoid was not detected at low dose of $12.5 \mathrm{mg}$ one hour after administration of the extract (Table 5).

Table 5. Systemic exposure of secondary metabolites of NLE in rat blood serum.

\begin{tabular}{llll}
\hline \multirow{2}{*}{ Metabolites } & reagents & \multicolumn{2}{l}{ Blood serum containing different doses of NLEa } \\
\cline { 2 - 4 } & & $\mathbf{1 2 . 5} \mathbf{~ m g}$ & $\mathbf{2 5} \mathbf{~ m g}$ \\
\hline Mucilage & Excess EtOH & + & ++ \\
Catechic tannins & STIASNY & + & + \\
Flavonoids & $\mathrm{NaOH}$ & - & + \\
Total polyphenols & $\mathrm{Lead}$ acetate & ++ & ++ \\
Tannins & $\mathrm{Cu} \mathrm{citrate}+\mathrm{NH}_{3}$ & +++ & ++ \\
Phlobotannins & $\mathrm{HCl}$ & - & - \\
\hline
\end{tabular}

Key: $+=$ low concentration; $++=$ moderate concentration; $+++=$ high concentration .

\section{Discussion}

Azadirachta indica, a tree stemming from the meliaceae family, is not a native tree of Cameroon. It was introduced in the drought prone North and Far North regions of Cameroon in the late $19^{\text {th }}$ century $[2,32-35]$. The acute toxicity studies done on the aqueous extract of Azadirachta indica, according to OECD 420 Guidelines was fixed at $2000 \mathrm{mg} / \mathrm{Kg}$. the fixed dose procedure was used and shown to be better for the acute toxicity testing as it doesn't consider the death of animals as the endpoint of toxicity studies uses fewer animals to produce similar result to toxicity studies done using the classical method [32-35]. At this dose, no sign of toxicity or lethality was observed. These results obtained are similar to those obtained by Kanagasanthosh et al, who also didn't experience any animal death at the dose of $2000 \mathrm{mg} / \mathrm{Kg}$. The LD50 was not determined in this study. Nonetheless, others have done studies beyond what was done in this case. At $2500 \mathrm{mg} / \mathrm{Kg}$, Dorababu et al didn't observe any mortality either [36]. This suggests the safe nature of $A$. indica, as it correlates with the traditional use for centuries [2, 37]. However, our results were different from the overall results obtained by Ashafa et al, who found out that at all doses used, the ethanolic extract of $A$. indica demonstrated toxicity [3840]. At a dose of $3200 \mathrm{mg} / \mathrm{Kg}$, Yinusa et al obtained a 100\% mortality in rats [12]. Contrarily, Adinortey et al found out that at a dose as high as $5000 \mathrm{mg} / \mathrm{Kg}$, a combination of an aqueous extract of $A$. indica with an ethanolic extract of Ficus racemose in a ratio 1:1 caused no lethality. Probably, a combination of these two extracts dampens the toxic effect. His results suggest that the $\mathrm{LD} 50$ is $>5000 \mathrm{mg} / \mathrm{Kg}[13,41]$.

Animals were observed on day one for thirty minutes for any behavioral changes and slight agitation were noticed in some animals. This happened just for the first day and the animals returned to their normal calm state, like the animals of the control group for the rest of the study period. This is different from what Kanagasanthosh observed when he noticed no behavioral changes in his test animals [24, 42]. This slight agitation could have resulted from the fact that the animals were fasted before the administration of the leaf extract. Also, the process of gavage is never comfortable for the animals. We observed that there was a progressive increase in the body weight of all animals, whether test or control. This could be explained by the fact that the animals were fasted before the beginning of the experiment, but during the experiment, they were given free access to food. This could also mean that the extract enhances a sense of taste and appetite of the animals. These results correspond to what was observed by Ashafa et al. On the other hand, we observed a decrease in the water intake. This is similar to what Ashafa observed in rats taking $300 \mathrm{mg} / \mathrm{Kg}$ [43].

In this study, we also realized that there was no significant difference in the weight of organs, as compared to the control groups of animals. These results corroborate with those obtained by Dias et al [21, 44]. This is however different from what Dorababu and Ashafa obtained. This could be because he used a dose higher than what we used (2500 $\mathrm{mg} / \mathrm{Kg}$ ). This difference might have been because they used the barks and not the leaves. From the analyses of the histological cuttings of the livers and kidneys of all animal groups, there was no change observed in the cellular morphology. Biochemical parameters were used to measure the proper functioning of the metabolic and various endocrine systems and as earlier seen, nutritional functioning 
or disorders. It is important to measure these parameters because they are useful in evaluating the functioning of various organs and in calculating damage percentages [28, 45]. The study recorded, upon the administration of the NLEa to test groups, a non-significant decrease of ASAT and a non-significant increase of ALAT on male test groups. No difference was observed in female groups, when compared to the control groups. This demonstrates the hepatoprotective abilities of the leaf extract. These results are similar to those obtained by Boadu et al [18]. He carried out this study in rabits in 2011 and found no significant difference in the levels of ASAT and ALAT, when compared to the control group of animals. Determination of serum electrolytes, creatinine and urea are critical as they are the important markers of kidney function. In this study, there was a significant increase in the creatinine levels in both female and males groups with a $p$-value $<0,001$ indicating that the renal function is negatively affected by this plant. The increase in total proteins without a damage in the kidneys or liver could mean that the plant has a high nutritional value.

\section{Conclusion}

According to this study, Azadirachta indica aqueous leaf extract contains active metabolites coumarins, catechic tannins, polyphenols, tannins, flavonoids and phlobotannins that were bioavailable in systemic circulation. Showed bioavailability at the tested doses $(12.5,25$ and $50 \mathrm{mg} / \mathrm{Kg})$, with the presence of phytochemicals being dose dependent. A clean toxicity profile, with just a slight increase in the level of creatinine.

\section{Consent}

It is not applicable.

\section{Ethical Considerations}

Ethical approval was taken from the institutional review board of the Faculty of Medicine and Biomedical Sciences. Authorization was obtained from the head of the laboratory of preclinical animal studies and toxicology research of the faculty of medicine and biomedical sciences (FMBS), of the University of Yaoundé I.

\section{Competing Interests}

Authors have declared that no competing interests exist.

\section{Acknowledgements}

The authors wish to thank the National Herbarium of Cameroon, Yaoundé for autentification of plant. The laboratory for preclinical animal studies and toxicology research of the Faculty of Medicine and Biomedical Sciences, FMBS, University of Yaoundé I for the technical and financial support. The New York University Medical Centre, Department of Pathology for researcher travel grant funding.

\section{References}

[1] WHO | About us [Internet]. WHO. [cited 2018 Apr 25]. Available from: http://www.who.int/traditionalcomplementary-integrative-medicine/about/en/.

[2] Wachtel-Galor S, Benzie IFF. Herbal Medicine: An Introduction to Its History, Usage, Regulation, Current Trends, and Research Needs. In: Benzie IFF, Wachtel-Galor S, editors. Herbal Medicine: Biomolecular and Clinical Aspects [Internet]. 2nd ed. Boca Raton (FL): CRC Press/Taylor \& Francis; 2011 [cited 2018 Apr 25]. Available from: http://www.ncbi.nlm.nih.gov/books/NBK92773/.

[3] Jo R, Am L, R C. Use of Herbal Medicines and Implications for Conventional Drug Therapy Medical Sciences. Altern Integr Med. 2013 Jul 19; 2 (6): 1-6.

[4] Petrovska BB. Historical review of medicinal plants' usage. Pharmacogn Rev. 2012; 6 (11): 1-5.

[5] Jain A, Choubey S, Singour PK, Rajak H, Pawar RS. Journal of Applied Pharmaceutical Science. Sida cordifolia Linn Overv. 2011; 01 (02): 23-31.

[6] Kumar VS, Navaratnam V. Neem (Azadirachta indica): Prehistory to contemporary medicinal uses to humankind. Asian Pac J Trop Biomed. 2013 Jul; 3 (7): 505-14.

[7] Ankoane F., Ngatcha G., Tagni-Sartre M., Biwolé S., Ndjitoyap N. Helicobacter pylori infection and peptic ulcer disease in children and adolescents. 2015 Dec; $1-4$.

[8] Bhusan Mohapatra B, Charan Das M, Dinda S, E. V. Nagoji K. Anti-ulcer activity of aqueous and ethanolic leaf extract of neem (Azadirachta indica) in albino rats. 2012 Feb 18;

[9] Sylvia. s Mader. The Digestive System. Understanding Human Anatomy \& Physiology. 5th ed. The McGraw-Hill Companies; 2004. p. 299-301.

[10] Gregory M. Gibbons. The Stomach [Internet]. Making Life Better through Research Education \& Healthcare; 2008 Nov 10; University of South Florida. Available from: http://health.usf.edu/nocms/medicine/internalmedicine/emerge ncymed/stomach.pdf.

[11] David I. Soybel. Anatomy And Physiology of the Stomach. Surgical Clinics of North America. North America: Elselvier Saunders; 2005. p. 875-94.

[12] Ian R. Daniels, William H. Allum. Anatomy and Physiology of the stomach [Internet]. 2017. Available from: http://eknygos.1smuni.lt/springer/463/17-37.pdf.

[13] O'Connor A, O'Moráin C. Digestive Function of the Stomach. Dig Dis. 2014; 32 (3): 186-91.

[14] Farrar GE, Bower IL, and RJ. Gastric Juice and Secretion: Physiology and Variations in Disease. Annu Rev Physiol. 1967; 29 (1): 141-68.

[15] Helander HF. Physiology and pharmacology of the parietal cell. Baillières Clin Gastroenterol. 1988 Jul 1; 2 (3): 539-54.

[16] McQuaid KR. Drugs Used in the Treatment of Gastrointestinal Diseases. BASIC \& CLINICAL PHARMACOLOGY. 13th ed. McGraw-Hill Education Lange; 2014. p. 1052-83. 
[17] Prabhu V, Shivani A. An Overview of History, Pathogenesis and Treatment of Perforated Peptic Ulcer Disease with Evaluation of Prognostic Scoring in Adults. Ann Med Health Sci Res. 2014; 4 (1): 22-9.

[18] Mertz HR, Walsh JH. Peptic ulcer pathophysiology. Med Clin North Am. 1991 Jul; 75 (4): 799-814.

[19] Kusters JG, van Vliet AHM, Kuipers EJ. Pathogenesis of Helicobacter pylori Infection. Clin Microbiol Rev. 2006 Jul; 19 (3): 449-90.

[20] Drini M. Peptic ulcer disease and non-steroidal antiinflammatory drugs. Aust Prescr. 2017 Jun; 40 (3): 91-3.

[21] Shier David, Lewis Ricki, Butler Jackie, Hole John. Hole's Human Anatomy and Physiology. Hole's Human Anatomy \& Physiology. 9th ed. McGraw-Hill, Boston; 2001.

[22] Bode CJ. Alcohol's Role in Gastrointestinal Tract Disorders [Internet]. Alcohol Rehab. [cited 2017 Nov 3]. Available from: http://alcoholrehab.com/alcoholism/alcohol-and-ulcers/.

[23] AL-Wajeeh NS, Hajerezaie M, Noor SM, Halabi MF, AlHenhena N, Azizan AHS, et al. The gastro protective effects of Cibotium barometz hair on ethanol-induced gastric ulcer in Sprague-Dawley rats. BMC Vet Res. 2017 Jan 19; 13: 27.

[24] Li LF, Chan RLY, Chan RLY, Lu L, Lu L, et al. Cigarette smoking and gastrointestinal diseases: The causal relationship and underlying molecular mechanisms (Review). Int J Mol Med. 2014 Aug 1; 34 (2): 372-80.

[25] Berndt V, Götz E, Schönleben K, Langhans P. [Stress-induced peptic ulcer; pathogenesis, clinical features, prevention and treatment (author's transl)]. Prakt Anasthesie Wiederbeleb Intensivther. 1978 Apr; 13 (2): 108-22.

[26] Zollinger-Ellison Syndrome: Background, Pathophysiology, Etiology [Internet]. [cited 2017 Nov 6]. Available from: https://emedicine.medscape.com/article/183555-overview.

[27] Tomassetti P, Campana D, Piscitelli L, Mazzotta E, Brocchi E, Pezzilli R, et al. Treatment of Zollinger-Ellison Syndrome. World J Gastroenterol WJG. 2005 Sep 21; 11 (35): 5423-32.

[28] Yang R-H, Chu Y-K. Zollinger-Ellison syndrome: Revelation of the gastrinoma triangle. Radiol Case Rep [Internet]. 2015 Dec 3 [cited 2017 Nov 6]; 10 (1). Available from: https://www.ncbi.nlm.nih.gov/pmc/articles/PMC4921170/.

[29] Milosavljevic T, Kostić-Milosavljević M, Jovanović I, Krstić M. Complications of Peptic Ulcer Disease. Dig Dis. 2011; 29 (5): 491-3.

[30] Dubero Sime. Gastroprotective Effect of Crude Ethanol Extract of Ethopian Propolis Against Chemical Induced Gastric Mucosal Lesion in Mice [Internet]. [Addis Ababa]: Addis Ababa University; 2007. Available from: http://etd.aau.edu.et/bitstream/123456789/2982/3/Microsoft\% 20Word\%20-\%20final.pdf.

[31] Fashner J, Alfred C. Gitu. Diagnosis and Treatment of Peptic Ulcer Disease and H. pylori Infection. American Acadamy of Family Physician. 2015 Feb; 91 (4): 236-42.

[32] Roche VF. The Chemically Elegant Proton Pump Inhibitors. Am J Pharm Educ [Internet]. 2006 Oct 15 [cited 2018 Apr 9]; 70 (5). Available from: https://www.ncbi.nlm.nih.gov/pmc/articles/PMC1637016/.
[33] Koelz HR. Protective drugs in the treatment of gastroduodenal ulcer disease. Scand J Gastroenterol Suppl. 1986; 125: 156-64.

[34] Bi W-P, Man H-B, Man M-Q. Efficacy and safety of herbal medicines in treating gastric ulcer: A review. World $\mathrm{J}$ Gastroenterol WJG. 2014 Dec 7; 20 (45): 17020-8.

[35] Shail Bala Sanghi. Diversity of Tree Flora at Tendukheda, District Narshinghpur, Madhya Pradesh. International Journal of Pharmacy \& Life Sciences. 2015 Jun; 6: 4562-4.

[36] El-Hawary SS, El-Tantawy ME, Rabeh MA, Badr WK. DNA fingerprinting and botanical study of Azadirachta indica A. Juss. (neem) family Meliaceae. Beni-Suef Univ J Basic Appl Sci. 2013 Mar 1; 2 (1): 1-13.

[37] Eid A, Jaradat N, Elmarzugi N. A Review of chemical constituents and traditional usage of Neem plant (Azadirachta Indica). (PMPJ). 2017 May 25; 2: 75-81.

[38] Mohammad A. Alzohairy. Therapeutic Role of Azadirachta indica (Neem) and their Active Constituents in Disease Prevention and Treatment. Evidence-Based Alternative and Complementary Medicine. 2016 Mar 1;

[39] Usman H, Abdulrahman F, Usman A. Qualitative Phytochemical Screening and In Vitro Antimicrobial Effects of Methanol Stem Bark Extract of Ficus Thonningii (Moraceae). Afr J Tradit Complement Altern Med. 2009 May 7; 6 (3): 289-95.

[40] Prashanth G. K., Krishnaiah G. M. Chemical composition of the leaves of Azadirachta indica Linn (Neem). International Journal of Advancement in Engineering Technology, Management \& Applied Science (IJAETMAS). 2014 Oct; 1 (5): 21-31.

[41] Chen X-Y, Chen H-M, Liu Y-H, Zhang Z-B, Zheng Y-F, Su $Z-Q$, et al. The gastroprotective effect of pogostone from Pogostemonis Herba against indomethacin-induced gastric ulcer in rats. Exp Biol Med. 2016 Jan; 241 (2): 193-204.

[42] OECD/OCDE. OECD guideline for testing of chemicals [Internet]. OECD/OCDE; 2001. Available from: https://ntp.niehs.nih.gov/iccvam/suppdocs/feddocs/oecd/oecd g1420.pdf.

[43] Nde DB, Emmanuel Ngu A, Immaculate Natang M. Physical properties of neem (Azadirachtaindicaa. juss) fruits, nuts and kernels. Sky Journal of Food Science. 2013 Dec; 2 (8): 014 23.

[44] Adinortey MB, Ansah C, Galyuon I, Nyarko A. In Vivo Models Used for Evaluation of Potential Antigastroduodenal Ulcer Agents [Internet]. Ulcers. 2013 [cited 2018 Feb 23]. Available from: https://www.hindawi.com/journals/ulcers/2013/796405/.

[45] Dash SP, Dixit S, Sahoo S. Phytochemical and Biochemical Characterizations from Leaf Extracts from Azadirachta Indica: An Important Medicinal Plant. Biochem Anal Biochem [Internet]. 2017 Jun 12 [cited 2018 Mar 21]; 6 (2). Available from: https://www.omicsonline.org/openaccess/phytochemical-and-biochemical-characterizationsfrom-leaf-extracts-fromazadirachta-indica-an-importantmedicinal-plant-2161-1009-1000323.php?aid=90323. 